\title{
MÉTODO, EXPOSIÇÃO E DEFINIÇÃO NA CRÍTICA DA RAZÃO PURA DE KANT ${ }^{1}$
}

\author{
METHOD, EXPOSITION AND DEFINITION IN KANT'S CRITIQUE OF PURE \\ REASON
}

Pedro Casalotti Farhat ${ }^{2}$

(gpedro.cfarhat@gmail.com)

\begin{abstract}
RESUMO
O objetivo deste artigo consiste em apresentar uma interpretação da Crítica da razão pura que parte da noção de método da filosofia e seu modo de exposição. Essa interpretação obedece ao imperativo de compreender a filosofia de Kant como um todo, o que exige, assim, indicar certa importância da noção de método no estudo da filosofia kantiana. Após adentrar as discussões preliminares com relação às interpretações do método da filosofia de Kant e o estabelecimento da importância dele, buscamos apresentar este método, distinguindo-o do que seria modo de exposição e passando a trabalhar seguindo principalmente o papel da definição no método filosófico, que se diferencia do apresentado no método matemático.
\end{abstract}

Palavras-chave: Método. Filosofia. Sistema. Kant.

\begin{abstract}
The aim of this article consists in presenting an interpretation of the Critique of Pure Reason that begins with the notion of method in philosophy and it is way of exposition. This interpretation obeys the imperative of comprehending Kant's philosophy as a whole and intends, doing do, point out the importance of the method in the study of kantian philosophy. After getting into the preliminary discussion about the possible interpretation of Kant's method of philosophy and its importance, we present the method, distinguishing it from the way of exposition. After that, we present the difference between the hole of definition in mathematics and philosophy.
\end{abstract}

Key words: Method. Philosophy. System. Kant.

\section{INTRODUÇÃO}

\footnotetext{
${ }^{1}$ Artigo originado de pesquisa financiada pela FAPESP.

${ }^{2}$ Graduando em Filosofia pela Universidade Federal do ABC.

CV Lattes: http://lattes.cnpq.br/4291687026108903.

ORCID: https://orcid.org/0000-0001-6575-0011.
} 
As interpretações da Crítica da razão pura $^{3}$ sempre foram palco de grandes discussões, desde os primeiros questionamentos de Jacobi e Schulze com relação ao problema da coisa em si e a suposta aplicação dos conceitos do entendimento a ela por parte de Kant ${ }^{4}$. Essa discussão específica sempre foi de grande interesse para a pesquisa e representa uma perspectiva fundamental na discussão acerca da filosofia de Kant. No entanto, uma outra interpretação polêmica, dessa vez acerca da sistematicidade da filosofia, presente em certa medida na compreensão de Arthur Schopenhauer ${ }^{5}$, mas resgatada pela interpretação de N. K. Smith ${ }^{6}$ de maneira mais madura, apresenta uma perspectiva contrária à possibilidade de uma composição e exposição verdadeiramente sistemática da filosofia. Essa última perspectiva questiona qual o motivo de Kant apresentar a Crítica repleta de passagens aparentemente escritas em períodos diferentes, mas montadas como se fossem um todo completo e coerente, enquanto a verdade, para os comentadores críticos mencionados, seria que

Kant praticamente contradiz a si mesmo em quase todo capítulo; e dificilmente há um termo técnico que não tenha sido empregado por ele em uma variedade de diferentes e conflituosos sentidos. Ele é o menos exato de todos os grandes pensadores. (SMITH, 1915, p. 527) ${ }^{7}$

\footnotetext{
${ }^{3}$ A edição de referência em português que utilizamos é Kant, I. Crítica da razão pura. Tradução de Fernando Costa Mattos. $4^{a}$ ed. Petrópolis, RJ: Vozes, Bragança Paulista, SP: Editora Universitária São Francisco, 2015. Após toda citação da Crítica se seguirá a paginação do original alemão, sendo A para a primeira edição (1781) e B para a segunda edição (1787) seguindo o modelo (KrV: A XXX ou B XXX). Para os demais textos de Kant, utilizaremos a paginação oficial da edição da Academia de Ciências de Berlim, com uma abreviação do título da obra antes do volume e da página. Exemplo: para referência aos Prolegômenos, que se encontram no volume IV da edição da Academia, no caso da página 285, segue referência como (Prol: IV 285). As referências completas das traduções da Crítica e dos demais textos de Kant utilizados são indicados ao final, onde constam as edições em alemão e outras línguas modernas.

${ }^{4}$ Sobre estas críticas e o chamado "problema da afecção" a que elas se referem, conferir Hulshof (2011, pp. 2 ss.) e Mattos (2009, pp. 80-1).

${ }^{5}$ Schopenhauer, em sua famosa crítica da filosofia kantiana, revela uma das primeiras faces da crítica à possibilidade do sistema da razão: "[...] uma característica inteiramente peculiar do espírito de Kant é uma satisfação singular pela simetria, que ama a multiplicidade variegada, para ordená-la e repetir a ordem em subordens, e assim por diante, exatamente como nas igrejas góticas. Sim, às vezes ele leva isto até a brincadeira, e então, por amor a essa inclinação, vai tão longe que pratica violência manifesta contra a verdade [...]" (Schopenhauer, 2005, p. 541).

${ }^{6}$ Sobre essas interpretações, conferir o trabalho de H. J. Paton (2007 [1936]), especialmente sua introdução, onde as interpretações de Vaihinger e do "patchwork method" ou "método da colcha de retalhos" (tradução livre) descrito por Smith (1915) são discutidos. A abordagem de Paton é interessante neste debate na medida em que pretende remediar essa interpretação, que poderia simplesmente acabar com a possibilidade da filosofia de Kant ser compreendida como um todo, tornando-a um mero agregado de pensamentos confusos.

${ }^{7}$ Trecho original: "Kant flatly contradicts himself in almost every chapter; and that there is hardly a technical term which is not employed by him in a variety of different and conflicting senses. He is the least exact of all the great thinkers".
} 
Diante dessas críticas severas, Paton (2007 [1936]) reconhece a dificuldade em sustentar a perfeição da obra e aponta quais seriam alguns dos problemas que ela apresenta, tanto com relação ao tempo de redação, quanto acerca da edição e aos erros técnicos, algo que o próprio Kant assume como existentes (cf. KrV: A XXI-XXII). No entanto, uma passagem de suas considerações mostra como a Crítica demanda que um tipo de interpretação específica ocorra para que possamos compreender o que Kant quis dizer:

Eu não defendo essa falta de cuidado com a expressão, nem sustento que as contradições são sempre meramente verbais; mas eu assevero que com o exercício de um pouco de inteligência e boa vontade, muitas das contradições alegadas vão desaparecer. (PATON, 2007 [1936], p. 51) ${ }^{8}$

Mas como interpretar ou ler a Crítica de maneira inteligente e com boa vontade? Uma leitura ativa, ou ainda, um "novo leitor" é exigido pela Crítica para que se possa compreender o que Kant está pretendendo dizer. Suzuki (1998) retoma esse assunto:

Esse leitor capaz de usar a própria razão e pensar por si mesmo não é possível somente a partir da crítica, porque nasce junto com a crítica. A atividade do leitor, como se espera mostrar, é decisiva no processo de formação e autocompreensão do que seja a filosofia crítica". (SUZUKI, 1998, p. 22)

A auto compreensão, apesar de revelar certo caráter subjetivo do procedimento filosófico, expressa-se somente na relação entre a obra de Kant e o leitor que busca interpretála. Considerado isso, em uma interpretação que segue tais parâmetros não se trata de alegar que os problemas enfrentados por ela refletem as incongruências textuais da obra (como fez Smith), mas sim que, como Kant afirma, uma interpretação de sua filosofia deve levá-la em consideração "como um todo". Essa é a compreensão que demanda o "exercício de um pouco de inteligência e boa vontade", segundo compreendemos, e o que Kant considera como uma visão do conjunto sistemático da filosofia. Em um trecho, no início dos Prolegômenos (1783), Kant expressa essa compreensão:

Só que a razão pura é uma esfera de tal modo à parte, tão completamente unificada em si, que não se pode tocar em nenhuma parte sem afetar todas as outras, e que nada se pode fazer sem primeiramente ter determinado o lugar de cada uma e a sua influência sobre as outras; porque, nada existindo fora dela que possa corrigir o nosso juízo interior, a validade e o uso de cada parte

\footnotetext{
${ }^{8}$ Trecho original: "I do not defend these carelessnesses of expression, nor do I maintain that the contradictions are always merely verbal; but I do assert that, with the exercise of a little intelligence and good will, many of the alleged contradictions will disappear".
} 
depende da relação em que ela se encontra com as outras na própria razão tal como, na estrutura de um corpo organizado, o fim de cada membro só pode deduzir-se do conceito geral do todo. (Proleg: IV 263) $)^{9}$

Dependemos de uma interpretação que leve em conta, portanto, algumas regras no proceder filosófico de Kant, que nos impeça de estabelecer uma interpretação partindo de apenas uma sentença ou apenas uma obra, pois dada a interdependência entre os mais diversos elementos de seu sistema, isso torna-se impossível. Veremos também mais à frente que, para complexificar a interpretação, poderíamos entender diferentes formulações do sistema como obedecendo ao desenvolvimento de certos problemas através do tempo.

No entanto, retomando a questão da interpretação, pode-se notar que isso revela uma tentativa de compreender Kant antes mesmo de sentenciá-lo à completa incongruência, pretendendo levá-lo a sério antes de considerar suas posições como meramente contraditórias. Analisemos uma passagem que nos auxilia na compreensão do motivo pelo qual devemos interpretar a filosofia de Kant sistematicamente:

Se denominarmos sensibilidade à receptividade de nossa mente para receber representações, na medida em que ela é afetada de algum modo, então o entendimento, por outro lado, é a faculdade de produzir representações por si mesma, ou a espontaneidade do conhecimento. É próprio de nossa natureza que a intuição só possa ser sensível, i.e., que só contenha o modo como somos afetados pelos objetos. Por outro lado, a faculdade de pensar o objeto da intuição sensível é o entendimento. Nenhuma dessas propriedades pode ser preferida à outra. Sem a sensibilidade nenhum objeto nos seria dado, e sem o entendimento nenhum seria pensado. Pensamentos sem conteúdo são vazios, intuições sem conceitos são cegas. Por isso, tornar sensíveis os seus conceitos (i.e., acrescentar-lhes o objeto na intuição) é tão necessário quanto tornar compreensíveis suas intuições (i.e., colocá-las sob conceitos). Ambas as faculdades ou capacidades também não podem trocar suas funções. $O$ entendimento não pode intuir nada, e os sentidos nada podem pensar. (KrV: B 75)

O fato de Kant praticamente não mencionar a razão nesta passagem e nos desenvolvimentos da Estética Transcendental e da Analítica Transcendental da Crítica da razão pura não significa que o filósofo esqueceu o papel fundamental que a razão tem ao longo de toda a sua filosofia. Essa ausência ocorre, justificadamente, dado o contexto em que Kant está descrevendo essas capacidades, onde não parece importar por completo uma razão que pensa objetos sem referência alguma à intuição. Com isso em mente e através das descobertas

\footnotetext{
${ }^{9}$ Essa interpretação da filosofia de Kant "como um todo" é reconhecida também em KrV: B XLIV. Sobre isso, cf. Paton (2007 [1936], pp. 37 ss.).
} 
expostas ao longo da Crítica, logo fica evidente que, afastando-nos da sensibilidade, aparecem proposições que poderiam passar por objetivas, mas que em verdade não correspondem a nenhuma intuição ou objeto da sensibilidade. Neste sentido, devemos compreender "entendimento", no trecho acima, como uma faculdade de pensamento em geral, que engloba o sentido cognitivo, relativo à sua relação com a sensibilidade, mas que ainda guarda a possibilidade de um sentido metafísico, relativo ao seu uso transcendente, ainda não revelado pela Crítica neste ponto, e que consistirá no sentido estabelecido para a razão na Dialética Transcendental.

Tendo esse tipo de interpretação grande valor para compreender efetivamente o que Kant pretendeu dizer, o que nos interessa é encontrar a fonte dessa visão do todo, isto é, dessa sistematicidade (que passa a ser determinante na compreensão da filosofia de Kant). O filósofo mostra-nos que entende por Doutrina Transcendental do Método "a determinação das condições formais de um sistema completo da razão pura" (KrV: B 735-6). Isso é relevante pois o estudo do método e do sistema aparecem então relacionados, como se aquele pudesse determinar formalmente este. Mas qual é o sentido de método adotado por Kant e que poderia determinar formalmente essa sistematicidade de sua filosofia? Seria ele o mesmo método adotado pela tradição dogmático-racionalista imediatamente anterior à Kant? Vejamos como ele se posiciona perante essa opção:

Não havendo, pois, nem mesmo quanto ao conteúdo, nenhum dogma no uso especulativo da razão pura, então todo método dogmático é inadequado, quer seja emprestado à matemática, quer seja elaborado de uma maneira própria. Pois ele apenas oculta os defeitos e erros e engana a filosofia, cujo autêntico propósito é iluminar ao máximo todos os passos da razão. Mesmo assim, o método sempre pode ser sistemático. (KrV: B 765)

Neste sentido, não seguindo as orientações dogmáticas do racionalismo em questão de método, Kant precisa indicar um substituto. Veremos, a partir da próxima seção, como poderia haver a possibilidade de um método sistemático para além do método dogmático.

\section{AS FONTES DO SISTEMA: O MÉTODO}

Para encontrar a fonte do sistema, temos, portanto, de nos remeter ao método adotado por Kant para o filosofar, algo que encontramos explicitamente em algumas de suas obras, como a própria Crítica, mas também em escritos pré-críticos e 
posteriores à Crítica. Em outra passagem dos Prolegômenos, Kant apresenta uma compreensão fundamental acerca do método:

\begin{abstract}
Aqui está, pois, um tal plano [os Prolegômenos], depois de acabada a obra [a Crítica], que pôde ser estabelecido segundo o método [Methode] analítico, já que a própria obra teve absolutamente de ser redigida segundo o procedimento de exposição [Lehrart] sintético, a fim de a ciência apresentar todas as suas articulações como a estrutura de uma faculdade cognoscitiva muito peculiar, na sua ligação natural. (Proleg: IV 263)
\end{abstract}

O modo ou procedimento de exposição [Lehrart] da Crítica é explicitamente sintético no sentido que deve apresentar todas as articulações possíveis para a ciência, levando progressivamente a cabo mesmo as mais inconvenientes - não obstante necessárias — exposições. Vejamos como uma dessas articulações, apesar de possivelmente desconfortável, surge como necessária dentro da Crítica. Do ponto de vista da razão pura especulativa, é estritamente necessário que apresentemos claramente nossas concepções acerca de coisas das quais não podemos ter qualquer intuição sensível e sobre as quais não podemos, por conseguinte, aplicar nossos conceitos. Estas coisas são as coisas em si mesmas, as quais não podem servir como objetos de uma intuição possível, e são, portanto, além de conceito-limite, problemáticas em relação à sua existência, o que pode tornar extremamente confuso determinar se Kant supõe ou não sua existência para o funcionamento de sua filosofia. A distinção fundamental entre as coisas em si mesmas e como elas aparecem para nós, isto é, como fenômenos dentro de certas condições sensíveis ou formas puras da sensibilidade (tempo e espaço), é importante pois impede que possamos conhecer coisas das quais nenhum objeto nos é dado e é discutida na Crítica, junto de diversos temas que não são objeto dos Prolegômenos. Esse é um exemplo de questão que surge em uma exposição progressiva e que é deixada de lado no modo de exposição regressivo dos Prolegômenos.

Isso ocorre pois os Prolegômenos não podem possuir o mesmo modo de exposição da Crítica, devendo ser denominado analítico, na medida em que não faria a exposição progressiva completa das articulações do sistema como um todo, mas apenas de um aspecto: no que ele afeta a possibilidade de fundamentação das ciências. Como veremos mais à frente, não devemos confundir o modo de exposição e o método ou procedimento de fazer filosofia. No caso da Crítica, o modo de exposição é sintético e o método teria dois sentidos, um primeiramente negativo (meramente analítico) e um segundo, relacionado à prova transcendental ou dedução, que é sintético (LOPARIC, 2005, pp. 33-79). No caso dos Prolegômenos, o modo de exposição é analítico e seu método também, não havendo, 
portanto, qualquer elemento sintético, seja no modo de exposição, seja no método dessa última obra. Vejamos mais um trecho dos Prolegômenos:

Na Crítica da razão pura procedi sinteticamente [synthetisch zu Werke gegangen] com relação a esta questão, isto é, investiguei na própria razão pura e procurei determinar, segundo princípios, nesta mesma fonte, tanto os elementos como as leis do seu uso puro. Este trabalho é difícil e exige um leitor decidido a penetrar pouco a pouco pelo pensamento num sistema que não põe como fundamento nenhum dado a não ser a própria razão e que procura, pois, sem se apoiar em qualquer fato, tirar o conhecimento a partir dos seus germes originais. (Proleg: IV 274, tradução modificada)

Novamente, o leitor descrito páginas acima por Suzuki é indicado aqui, mostrando que há uma necessidade, desde a época de Kant, em incrementar a leitura e interpretação filosófica para além de uma mera apreensão passiva. As distinções e análises conceituais apresentam-se, com isso, necessárias para atravessar o percurso da Crítica e, por conta de sua abrangência, seu procedimento sintético é trabalhoso, na medida em que precisamos progressivamente derivar todas as consequências de cada uma das distinções e provar as relações entre os diversos elementos.

A vantagem do modo de exposição sintético seria o de que ele não pressupõe nada a não ser uma razão (ainda que indefinida) e parte de conceitos confusos para ir refinando suas concepções. No caso da análise do conceito de razão humana em geral, único pressuposto, este é o projeto da Crítica. Nos Prolegômenos, seu procedimento analítico percorre o caminho inverso e, supondo já feita a Crítica e sem discutir distinções fundamentais para esta (portanto supondo-os como desinteressantes para a questão que trata), como a legitimidade da ligação entre as intuições e os conceitos (algo que ocorre na dedução das categorias), expõe a filosofia por um caminho particular, deixando de lado suas articulações sistemáticas "como um todo".

Por conta disso, as noções apresentadas no texto, longe de não terem qualquer valor em si, podem e talvez devam ser lidas tomando como ponto de vista algo que Kant nos diz no prefácio à segunda edição da Crítica:

A tarefa principal desta crítica da razão pura especulativa reside nessa tentativa de modificar o procedimento até hoje adotado na metafísica, e isso de tal modo que operemos uma verdadeira revolução da mesma a partir do exemplo dos geômetras e dos pesquisadores da natureza. Ela é um tratado do método, não um sistema da própria ciência; mas ela circunscreve ao mesmo tempo o seu inteiro contorno, tanto com relação às suas fronteiras [Grenzen] quanto com relação a toda a sua estrutura interna. Pois a razão pura especulativa tem isso de próprio: ela pode - e deve medir a sua própria faculdade segundo a diversidade dos modos 
pelos quais escolhe objetos para o pensamento, e também enumerar completamente os diversos modos de colocar-se tarefas, delineando assim o esboço completo para um sistema da metafísica. (KrV: B XXII-XXIII, tradução modificada e grifo nosso $)^{10}$

Deste modo, surge uma concepção dupla da Crítica que se constitui pelo seguinte: primeiro, compreende-se que a crítica da razão pura especulativa é um tratado do método, e segundo, que a crítica da razão pura especulativa não é um sistema da própria ciência metafísica. No entanto, esta compreensão é problemática e podemos tentar considerar mais a fundo o parágrafo citado. Um terceiro elemento faz-se presente e modifica a interpretação, a complexificando: mesmo sem ser o sistema da própria ciência, a Crítica circunscreve ao mesmo tempo o seu inteiro contorno, tanto com relação às suas fronteiras quanto com relação a toda a sua estrutura interna. Este fator é essencial para compreender que a Crítica, seguindo esta leitura - vale dizer, iniciada pelo próprio Kant ao comentar a segunda versão de sua obra, em 1787 - não tem por resultado apenas um método para o sistema da ciência por vir, mas também, e principalmente, os princípios que orientam criticamente essa filosofia.

Delinear "o esboço completo para um sistema da metafísica" é menos indicar-lhe o caminho correto e mais orientar a si mesmo enquanto ciência. Neste sentido, a razão tem o direito de auto submeter-se ao próprio exame de suas capacidades e das representações que as concernem. Trata-se, na Crítica, dos traços fundamentais sem os quais não seria possível um verdadeiro sistema da metafísica. As fronteiras do sistema estão relacionadas com o conhecimento que somos capazes de ter, e não apenas com o conhecimento que já possuímos: a orientação do método da filosofia está relacionada precisamente com as nossas possibilidades de conhecimento.

Claro que, dentro desta hipótese, ao menos duas outras nos acompanham: o sentido de metafísica que Kant defende é outro, muito diferente daquele das metafísicas anteriores, pois, se antes pretendia-se ir aos objetos neles mesmos, ou ainda, a qualquer objeto inteligível, Kant pretende, com essa nova metafísica, declarar inaptos os esforços de desenvolver qualquer ciência para além dos objetos de nossa experiência possível. A caracterização da metafísica de Kant é o que ele chamou, em outro momento, de metafísica aplicada ou doutrinal (TREVISAN, 2014, p. 106).

\footnotetext{
${ }^{10}$ Sempre que ocorrerem modificações nas traduções adotadas, indicaremos em nota o seu motivo, a não ser que essa modificação já tenha sido explicada antes. Grenzen (fronteiras) envolvem o conhecimento humano como um todo, enquanto Schranken (limites) envolvem apenas conhecimentos particulares, como o das ciências. Sobre essa distinção, cf. KrV: A VIII, B XIX-XXI, B XXIV, B 789-91; Prol: IV 351, bem como Moore (2010, p. 322).
} 
Uma segunda mudança é o objeto propriamente dito de nosso estudo aqui: trata-se de uma nova concepção de método da filosofia. Tal método é indicado implicitamente e exemplificado no prefácio à segunda edição da Crítica, em uma nota de rodapé:

Este método [...] poderá trabalhar com conceitos e princípios que assumimos a priori, na medida, de fato, em que eles sejam estruturados de tal forma que os mesmos objetos possam ser considerados por um lado como objetos dos sentidos e do entendimento para a experiência, mas por outro como objetos, próprios à razão isolada que ultrapassou toda fronteira da experiência [Erfahrungsgrenze], que só podem ser pensados; os objetos são, portanto, considerados de dois lados distintos. Se se verifica então, quando as coisas são consideradas desse duplo ponto de vista, que ocorre uma concordância com o princípio da razão pura, ao passo que de um único ponto de vista surge um conflito inevitável da razão consigo mesma, então o experimento decide pela legitimidade de tal distinção. (KrV: B XVIII-XIX).

Nesta passagem, por meio do problemático conceito de "objeto" evidenciou-se uma diferença fundamental nas maneiras de considerá-lo, o que possibilita estabelecer uma distinção que pode valer de maneira a nos fazer compreender melhor o conceito de algo, antes obscuro para nós, evitando um conflito evidente da razão. Essa explicação revela o método da filosofia implicitamente, o que por sua vez permite-nos compreender um pouco melhor as fontes da distinção entre fenômeno e coisa em si, neste caso. Essa é apenas uma das distinções que Kant opera na Crítica, tomando como base um conceito, mas partindo do problema mais geral da análise de uma razão pura especulativa (a determinação de suas capacidades está pressuposta, portanto, para uma compreensão do conceito).

A tese apresentada por Caimi (2012) na aplicação do método que Kant indica ser o método da filosofia na estrutura e divisões gerais da Crítica consiste na ideia de que ela busca definir ou esclarecer a noção de razão pura especulativa. Tal tese parece funcionar, na medida em que o método da filosofia deve proceder de maneira analítica, expondo cada uma das notas características de dado conceito, inicialmente apresentado de maneira confusa (CAIMI, 2012, p. 9), e justificando tal distinção por uma prova sintética, em que tal distinção torna-se legítima e necessária. Para melhor entender essa tese, portanto, precisamos entender qual o método que Kant obedece.

Para compreender como Kant considera tal método, ao menos parcialmente, no que tange aos problemas enfrentados aqui, precisamos passar agora a trabalhar diretamente com a Doutrina Transcendental do Método da Crítica da razão pura. Discutiremos, a princípio, o que seria o método da filosofia, distinguindo-o mais precisamente do modo de exposição e depois como o método da filosofia lida com a definição, uma 
noção proveniente da matemática e que se torna uma opção vedada através do bloqueio do método dogmático.

\section{O MÉTODO E O MODO DE EXPOSIÇÃO DA FILOSOFIA}

O método [Methode] da filosofia diferencia-se de seu modo de exposição [Lehrart] por conter apenas as regras do proceder filosófico e não a maneira como este deve ser apresentado. Neste sentido, como já adiantamos, existem diferentes compreensões do modo de proceder e o modo de expôr da filosofia de Kant: do ponto de vista do método da filosofia, somente seria possível proceder analisando e esclarecendo conceitos antes confusos, que agora poderiam ser mais bem explicados (KrV: B 740 ss.). Neste sentido, a síntese está limitada ao método de prova como o da dedução transcendental das categorias (KrV: B 810 ss.).

De outro ponto de vista, isto é, do modo de exposição, a Crítica somente poderia ser exposta sinteticamente (como indicam os trechos já citados dos Prolegômenos), pois esta deveria compreender progressivamente as articulações completas do sistema da razão. Seguindo o método de exposição, no entanto, os Prolegômenos, por exemplo, funcionam regressivamente, seguindo uma única linha de raciocínio, um único fio condutor em sua exposição, que pressupõe, além do mais, a Crítica. Nossa preocupação aqui será expor como surge a noção de 'método da filosofia', isto é, o proceder filosófico analítico, deixando de lado as considerações sobre a possibilidade de uma prova transcendental através de uma dedução, intentando aqui mostrar meramente como o método enquanto análise e exposição é fundamental na compreensão da Crítica.

A filosofia, neste contexto, deve ser encarada como um "conhecimento racional por conceitos, que é denominado filosófico" (KrV: B 752). Um conhecimento desse tipo quer dizer que na filosofia somente poderíamos proceder através da análise de conceitos, discursivamente (KrV: B 760), sem recorrer a qualquer intuição, seja ela pura (apenas nas formas puras da sensibilidade) ou sensível (por meio de fenômenos que recebemos através das formas puras da sensibilidade). Feita a análise, poderíamos buscar, através das provas transcendentais, uma síntese possível, que é, no entanto, limitada ao configurar apenas a ordem de legitimidade dos conceitos.

No caso de expormos intuições puras, Kant defende que se procederia através do método próprio da matemática, em que necessariamente deve haver uma construção do conceito por meio da intuição, mas estaríamos então fora do campo 
da filosofia. A diferença entre conhecimento discursivo e conhecimento por construção é fundamental para mostrar a diferença entre os métodos da matemática e da filosofia. Vejamos como Kant compreende a construção:

Construir um conceito [...] significa expor a intuição a priori a ele correspondente. Para a construção de um conceito, portanto, é exigida uma intuição não empírica, e esta, por conseguinte, é, enquanto intuição, um objeto singular, mas nem por isso tem de exprimir na representação, como construção de um conceito (de uma representação universal), validade universal para todas as intuições possíveis que caibam sob o mesmo conceito. $(\mathrm{KrV}: \mathrm{B} 741)$

Importa-nos compreender que a construção de uma figura geométrica ou de uma equação matemática envolve uma intuição pura (no caso da figura, intuição pura do espaço e no caso da equação, intuição pura do tempo). Dessa intuição encontramos a universalidade "no singular" (KrV: B 742), isto é, as propriedades de uma figura geométrica qualquer, que entretanto valem para aquele tipo de figura em geral, modificando-se apenas as características que não transformam sua construção espacial. Uma construção qualquer no espaço puro (independente da experiência) nos permite determinar as propriedades desse tipo de figura que são válidas para quaisquer outras figuras semelhantes sem recorrer à experiência para legitimar o argumento através de uma indução. Por outro lado, também não utilizamos uma demonstração lógica dessa propriedade da figura, restando apenas que ela seja construída para que tenha suas propriedades estabelecidas. As considerações de Kant acerca do método da matemática abrem possibilidades de expansão para os conhecimentos desta ciência, deixando a filosofia aparentemente limitada ao mero proceder analítico, em que não se pode recorrer às intuições sem recorrer a imitação da matemática.

O conhecimento racional por conceitos, com isso, está impedido de qualquer construção teórica (pois esta envolve uma intuição), e deve ser sempre guiado pela necessidade de esclarecimento de conceitos, os quais poderiam assim ser reunidos levando em conta as necessidades racionais (as capacidades e faculdades humanas). Nunca devemos esquecer que, caso tais conceitos devam determinar a experiência ou ser construídos, estes escapam do campo da filosofia e passam a depender de experiências físicas nas intuições sensíveis ou construções matemáticas na intuição pura. Caso um conceito, como 'Deus', tenha pretensões objetivas (na experiência), ele depende de intuições sensíveis, as quais estavam a princípio impedidas para a filosofia. Portanto, tal pretensão do conceito impede uma prova de tipo não apenas conceitual da existência do objeto possível a que se refere 'Deus' (e que não passa, 
desse modo, de mera ideia ou conceito da razão pura, na medida em que jamais encontraremos uma experiência possível a que ele possa ser aplicado).

Os filósofos da tradição dogmático-racionalista na qual Kant foi formado e com a qual rompe cometem o equívoco de considerar o método matemático e o método filosófico como únicos e o mesmo ${ }^{11} \mathrm{e}$, com isso, também pretendem que uma prova conceitual de Deus, por exemplo, possa determinar objetivamente (na experiência) o conhecimento em geral (metafísico, físico, matemático etc). Isso ocorre, pois, a validade das provas matemáticas (por construção) poderiam, neste caso, ter a mesma validade das provas meramente conceituais (filosóficas) o que, no entanto, é impossível para Kant.

Desta maneira, como os métodos precisam ser distintos, todas as noções metodológicas fundamentais empregadas comumente em matemática e filosofia passam a ter sentidos diferentes (definições, axiomas, postulados, etc.). Trataremos da noção de 'definição', a qual é central para a matemática e para a filosofia, mesmo após tal separação metodológica, nos fornecendo um exemplo conceitual que ressoa até a filosofia contemporânea.

No método matemático, a definição, isto é, "expor o conceito completo de uma coisa, originariamente, no interior de suas fronteiras [Grenzen]" (KrV: B 755), não é apenas possível, mas intrinsecamente necessária, na medida em que envolve a construção de um conceito através da intuição. Essa construção permite que a partir da figura de um triângulo possamos encontrar as propriedades que nele não estão óbvias, como a de que a soma de seus ângulos internos é sempre igual a dois ângulos retos (KrV: B 744-5) ${ }^{12}$.

As definições, em filosofia, diferente do que ocorre na matemática, não devem ser o princípio da exposição pois, para Kant, a definição como exposição completa do conceito de

\footnotetext{
${ }^{11}$ Os seguintes trabalhos lidam com a formação de Kant e seu rompimento com a tradição em questão: Friedman (1998), Perez (1998), Carson (1999) e Schönfeld (2000).

${ }^{12} \mathrm{Em}$ Os elementos, Euclides nos apresenta esse mesmo caso na proposição 32, como nos indicam Guyer e Wood em sua tradução da Crítica. Cito Euclides: "32. Tendo sido prolongado um dos lados do triângulo, o ângulo exterior é igual aos dois interiores e opostos, e os três ângulos interiores do triângulo são iguais a dois retos. Seja o triângulo $\mathrm{ABC}$, e fique prolongado um lado dele, o $\mathrm{BC}$, até o $\mathrm{D}$; digo que o ângulo sob $\mathrm{ACD}$, exterior, é igual aos dois sob $\mathrm{CAB}, \mathrm{ABC}$, interiores e opostos, e os três ângulos sob $\mathrm{ABC}, \mathrm{BCA}, \mathrm{CAB}$, interiores do triângulo, são iguais a dois retos. Fique, pois, traçada, pelo ponto $\mathrm{C}, \mathrm{a} \mathrm{CE}$ paralela à reta $\mathrm{AB}$. $\mathrm{E}$, como a $\mathrm{AB}$ é paralela à $\mathrm{CE}$, e a $\mathrm{AC}$ caiu sobre elas, os ângulos sob $\mathrm{BAC}, \mathrm{ACE}$, alternos, são iguais entre si. De novo, como a $\mathrm{AB}$ é paralela à $\mathrm{CE}$, e a reta $\mathrm{BD}$ caiu sobre elas, o ângulo sob ECD, exterior, é igual ao sob $\mathrm{ABC}$, interior e oposto. Mas foi provado também o sob ACE igual ao sob BAC; portanto, o ângulo sob ACD todo é igual aos dois sob BAC, ABC, interiores e opostos. Fique adicionado o sob ACB comum; portanto, os sob ACD, $\mathrm{ACB}$ são iguais aos três sob $\mathrm{ABC}, \mathrm{BCA}, \mathrm{CAB}$. Mas os sob $\mathrm{ACD}, \mathrm{ACB}$ são iguais a dois retos; portanto, os sob ACB, CBA, CAB são iguais a dois retos. Portanto, tendo sido prolongado um dos lados de todo o triângulo, o ângulo exterior é igual aos dois interiores e opostos, e os três ângulos interiores do triângulo são iguais a dois retos; o que era preciso provar" (Euclides, 2009, p. 122). Para uma interpretação da relação entre as partes da demonstração de Euclides e a compreensão de Kant, cf. Hintikka (1967, pp. 361 ss.)
} 
alguma coisa dentro das suas fronteiras é inalcançável para a filosofia e deve servir apenas como sua meta, mesmo que inalcançável.

[...] eu nunca posso estar seguro de que a representação clara de um conceito dado (ainda confuso) foi exaustivamente desenvolvida, a não ser que eu saiba que ela é adequada ao objeto. Como o conceito deste, porém, tal como é dado, pode conter muitas representações obscuras que não percebemos ao analisálo, muito embora o utilizemos sempre na aplicação, a completude da análise de meu conceito é sempre duvidosa e só pode ser tornada supostamente certa através de muitos exemplos adequados, mas jamais apoditicamente certa. (KrV: B 756-7)

Com essa compreensão, Kant também mostra que a mera presunção de indicar por um nome um conceito empírico de algo que, até onde podemos saber, provavelmente contém características que ainda nos são ocultas, não passa de uma mera "designação, não um conceito da coisa", o que o leva a considerar a definição apenas uma determinação da palavra e não da coisa ela mesma (KrV: B 756). Como substituta dessa palavra no uso racional discursivo, isto é, filosófico, Kant propõe "exposição [Exposition], que é sempre cautelosa e pode ser aceita pelos críticos até certo ponto, ainda que mantendo dúvidas quanto à sua completude" (KrV: B 757).

Partindo desta mudança, Kant reafirma o caráter de suposição das exposições filosóficas, as quais não apenas não conseguem ser fonte de certeza sempre, como também podem e estão muitas vezes erradas, "ou porque introduzem características que na verdade não estavam no conceito, ou porque carecem da completude, que é o essencial de uma definição" (KrV: B 760). A necessidade de a definição ser sempre dada na construção do conceito leva Kant a mostrar, pois, que esta definição, se tomada desde o início, somente pode ser utilizada em filosofia como experimento, sem resultados positivos, visto que na filosofia busca-se a explicação de conceitos ainda confusos e não de definições já pensadas. Por esta razão Kant enuncia o dito de que na filosofia deve a definição (como exposição) mais concluir o trabalho do que iniciá-lo (KrV: B 758-9).

Essa compreensão meramente analítica da filosofia é, em certo sentido, negativa, na medida em que está de acordo com as limitações impostas pela Crítica ao conhecimento metafísico (filosófico). Não haveria um motivo razoável, segundo o espírito desta obra, em supor que o conhecimento filosófico pudesse ultrapassar as limitações impostas pela experiência, pretendendo um conhecimento do mundo físico, ou melhor, através do modo como nos são dados os objetos [Gegenstande] enquanto fenômenos (da intuição). Na Dialética Transcendental foi realizada a análise e negação da 
possibilidade de a razão humana expandir seus domínios de conhecimento para objetos suprassensíveis, algo que, portanto, está de acordo com a impossibilidade, por exemplo, da filosofia relacionar representações diversas sinteticamente como a matemática faz.

Representação aqui significa tanto as intuições quantos os conceitos e, neste sentido, estão disponíveis à razão em seus diferentes usos. No uso matemático é possível que tais representações sejam arbitrariamente vinculadas ${ }^{13}$ e que se parta desta vinculação, enquanto definição, para as decorrentes derivações de tal disciplina. No uso filosófico permanecemos sem um elemento seguro anterior, uma definição, da qual se parte para os demais elementos do conhecimento. Neste sentido, a Crítica obedece ao método filosófico em sentido negativo ou analítico quando não põe nada como fundamento além da razão (Proleg: IV 274) e analisa fundamentalmente este conceito de razão pura especulativa ao longo de seu percurso completo (cf. CAIMI, 2012, p. 9). A exposição [Exposition] aqui apresentada parece ser a mesma que está associada ao modo de exposição [Lehrart] sintético da Crítica e por essa razão devemos tomar o cuidado de diferenciar o proceder filosófico do modo como esse proceder é exposto ou ensinado, pois o proceder analisa, enquanto a exposição apenas ensina essa análise. Necessário dizer que, no caso da Crítica, as coisas parecem coincidir apenas no que se refere ao fato dela expor qual o método que a filosofia deve obedecer, o que nem sempre é verdade na filosofia, pois nem sempre nesta área trata-se de uma exposição completa do sistema ou um tratado do proceder filosófico.

\section{CONSIDERAÇÕES FINAIS}

Algumas considerações ainda podem nos ser úteis na compreensão desse tópico em relação com a gênese da Crítica. Compreendendo essa necessária separação entre proceder e expor, passamos agora a tratar da importância de compreender o método adotado por Kant para a Crítica.

Caimi (2012), como já indicamos, é partidário da interpretação de que a Crítica obedece ao que Kant indica na Doutrina do Método e remonta essas reflexões metodológicas aos escritos

\footnotetext{
${ }^{13}$ No texto pré-crítico Investigação sobre a evidência dos princípios da teologia natural e da moral, de 1764 Kant utiliza da formulação "vinculação arbitrária" (Invest: II 276) para referir-se ao procedimento matemático. Neste texto, a mesma problemática é apontada, sem, no entanto, diversos elementos que seriam novidades da Crítica da razão pura como a compreensão das intuições puras e sensíveis. Para diferentes comparações entre tal texto e o da Doutrina do Método cf. Caimi (2012) e Beth (1966, pp. 41-7). Lebrun (2002, pp. 29-30) insere tal escrito pré-crítico na problemática da metafísica como Kant a encarava durante a gênese da Crítica.
} 
pré-críticos de Kant, mais especificamente a Investigação sobre a evidência dos princípios da teologia natural e da moral, de 1764. Essa anterioridade é o que verdadeiramente nos interessa de sua interpretação: a leitura da Crítica da razão pura como um "tratado do método" que obedece ao método de que fala e fala sobre o método que é necessário seguirmos em filosofia. Essa chave de leitura apresenta certa legitimidade na letra de Kant, mas também abre espaço para melhor compreender que a exposição da Crítica deve ser abrangente e progressiva, analisando todas as articulações internas da ciência, não sendo, no entanto, completa como uma definição e nem a própria ciência, mas um outro nível de julgamento, ainda que imanente ao conhecimento filosófico.

A questão que surge daqui é: seria a Crítica apenas mais uma parte da metafísica, na medida em que atua segundo o mesmo método desta? Essa parece ser a compreensão de Caimi, ainda que essa sua tendência não nos pareça positiva para a compreensão da Crítica, visto possivelmente nivelar suas teses com as teses dogmáticas e céticas, algo que Kant mesmo não parece considerar válido. A Crítica não está dentro do mesmo regime discursivo da metafísica tradicional, mas em outro nível discursivo e semântico, o qual envolve a tratativa de legitimidade da metafísica antes de se fazer metafísica. Neste sentido a Crítica é compreendida como propedêutica, antes de ser parte da metafísica (KrV: B 24-25 e B 869) e, portanto, a um mesmo tempo imanente e fora do sistema da razão.

A filosofia de Kant, muitas vezes interpretada como a apresentação de um sistema fixo e reiteradamente imóvel deve ser reposta, se não por um sistema que se adapte às novidades e diferentes situações, ao menos por um sistema dinâmico, que Kant mesmo poderia ter aperfeiçoado ao longo do seu desenvolvimento filosófico (cf. WERKMEISTER, 1980). A Crítica faz parte desse sistema na medida em que serve para determinar as fontes e as fronteiras, bem como o método de fazer filosofia a que o sistema está ligado.

A consideração da filosofia como orientada pelo método de esclarecimento de conceitos (sentido negativo) e por um modo de exposição específico faz com que se remonte à figura do professor [Lehrer], a que Kant faz referência, e que expõe a doutrina, mas não é apenas o ideal do próprio praticante de filosofia, mas também o de mestre dos trabalhadores da razão. "O matemático, o estudioso da natureza e o lógico", meros "artistas da razão" servem de "ferramentas para promover os fins essenciais [die wesentlichen Zwecke] da razão humana" (KrV: B 867), direcionados por tal mestre. No entanto, não devemos confundir a doutrina apresentada aqui pelo "mestre" com uma doutrina absoluta da verdade. Trata-se, de acordo com a metáfora kantiana e nossa compreensão do modo de exposição, de uma organização completa do conhecimento humano através de um sistema 
dinâmico, que seria possível aperfeiçoar através dos desenvolvimentos filosóficos. Werkmeister (1980) adianta essa compreensão: "Há unidade no pensamento de Kant, [...] mas é a unidade de desenvolvimento de um determinado problema no seu pensamento, não o de um preconcebido e estático sistema" (WERKMEISTER, 1980, p. i) ${ }^{14}$.

Após analisar esta noção de método e como ela se diferencia do modo de exposição, portanto, não podemos deixar de notar que haveria um interesse conceitual e historiográfico posterior ao que podemos tratar aqui, que é o de compreender melhor, no todo da obra de Kant, isto é, em cada um de seus textos, como o método opera, se ocorre da mesma maneira ou se teria uma outra configuração. Entretanto, como ressaltado, não pode haver qualquer afirmação da interpretação no sentido de um sistema de proposições fixas, antes mesmo de compreender ativamente a filosofia como esta foi exposta por Kant. Deixamos, no entanto, a possibilidade aberta para que essa pesquisa seja efetivada no futuro. Outro aspecto que não foi tratado nesse artigo, mas tem grande importância no estudo da filosofia kantiana é o aspecto positivo do método, relativo, como já dissemos, às provas transcendentais, e que deixamos igualmente em aberto.

Tendo compreendido que foi possível até aqui mostrar a importância do tratamento da noção de método em Kant, mostrando seu papel fundamental na determinação dos procedimentos e aspectos teóricos da própria Crítica, consideramos completos nossos objetivos neste artigo. Como indicado, buscamos apresentar uma certa perspectiva interpretativa de Kant que enfoca a Crítica da razão pura enquanto determinada, em certa medida, por uma compreensão metodológica, isto é, de como proceder e como expor uma filosofia. Esta interpretação, longe de pretender rechaçar outras chaves de leitura, busca compreender a filosofia de Kant como um todo, sem deixar de ver em suas obras as mudanças e nuances do desenvolvimento de seu sistema.

A interpretação de Caimi (2012) reflete parcialmente nossa compreensão, tendo sido aplicada por ele em outro trabalho, em que são apresentadas as "quatro chaves de leitura" da dedução transcendental dos conceitos (CAIMI, 2008). Na segunda chave de leitura, do "método sintético de exposição" (CAIMI, 2008, pp. 123-126), Caimi mostra como a dedução das categorias da Crítica mantém-se dentro dos limites impostos desde o texto pré-crítico mencionado, da Investigação sobre a evidência dos princípios da teologia natural e da moral

\footnotetext{
${ }^{14} \mathrm{O}$ trecho original diz: "Unity there is in Kant's thinking, [...] but it is the unity of a problemdetermined development in his thinking, not that of a preconceived or static system".
} 
até as determinações da Doutrina do Método, e acaba por verificar parcialmente a validade de tal interpretação.

Desejamos apenas indicar, portanto, por meio destas considerações finais, que para uma interpretação da filosofia de Kant, devem ser preenchidos os critérios de tentar compreender a filosofia de Kant como um todo e em suas diferentes modificações conceituais através de suas obras. 


\section{REFERÊNCIAS BIBLIOGRÁFICAS}

Obras de Kant:

KANT, Immanuel. Gesammelte Schriften herausgegeben von der Deutschen Akademie der Wissenschaften, anteriormente Königlichen Preussischen Akademie der Wissenschaften, 29 vols. Berlin: Walter de Gruyter, 1902-. Disponível em: <https://korpora.zim.uni-duisburgessen.de/kant/verzeichnisse-gesamt.html>, acesso dia 27/01/2019.

. Crítica da faculdade de julgar. Tradução de Fernando Costa Mattos. Petrópolis, RJ: Vozes; Bragança Paulista, SP: Editora Universitária São Francisco, 2016.

Crítica da razão pura. Tradução: Fernando Costa Mattos. $4^{\mathrm{a}}$ ed. Petrópolis, RJ:

Vozes, Bragança Paulista, SP: Editora Universitária São Francisco, 2015.

. Crítica da razão pura. Tradução de Manuela Pinto dos Santos e Alexandre Fradique Morujão. $8^{\mathrm{a}}$ ed. Lisboa: Fundação Calouste Gulbenkian, 2013.

. Crítica da razão pura. Tradução de Valério Rohden e Udo Baldur Moosburger.

$2^{a}$ ed. São Paulo: Abril Cultural, 1983. (Coleção Os Pensadores).

Crítica de la razón pura. Tradução de Mario Caimi et al.; Colaboração de

Esteban Amador, Mariela Paolucci, Marcos Thisted. México: Fondo de Cultura Económica, 2009.

Critique of Pure Reason. Tradução de Paul Guyer e Allen Wood. Cambridge,

USA: Cambridge University Press, 1999.

. Escritos pré-críticos. Traduções de Jair Barbosa, Joãosinho Beckenkamp, Luciano Codato, Paulo Licht dos Santos e Vinícius de Figueiredo. São Paulo: Editora UNESP, 2005 .

Prolegómenos a toda metafísica futura que haya de poder presentarse como ciencia. (Edição bilíngue). Edição, tradução, comentários e notas por Mario Caimi. Epílogo de Norbert Hinske. Madrid: Ediciones Istmo S. A., 1999.

Prolegómenos a toda a metafísica futura que queira apresentar-se como ciência. Tradução de Artur Morão. Lisboa: Edições 70, 1988.

Demais referências: 
BETH, E. W. The Foundations of Mathematics. New York: Harper \& Row, 1966.

CAIMI, M. Quatro chaves para a leitura da dedução transcendental. In: PERES, D. T. et al. (Orgs.). Tensões e passagens: filosofia crítica e modernidade. São Paulo: Esfera Pública Singular, pp. 121-30, 2008.

. Application of the Doctrine of Method in the critical examination of reason.

Studia Kantiana 13, p. 5-16, 2012.

CARSON, E. Kant on the Method of Mathematics. Journal of the History of Philosophy, v. 31, n. 4, pp. 629-652, 1999.

EUCLIDES. Os elementos. Tradução de Irineu Bicudo. São Paulo: Editora UNESP, 2009.

HINTIKKA, J. Kant on the mathematical method. The Monist 51, pp. 352-375, 1967.

HULSHOF, M. A 'coisa em si' entre teoria e prática: uma exigência crítica. Tese de Doutorado. São Paulo: Universidade de São Paulo, 2011.

LEBRUN, G. Kant e o fim da metafísica. Tradução de Carlos Alberto Ribeiro de Moura. $2^{\mathrm{a}}$ ed. São Paulo: Martins Fontes, 2002.

LOPARIC, Z. A semântica transcendental de Kant. $3^{\text {a }}$ edição. Campinas: UNICAMP, Centro de Lógica, Epistemologia e História da Ciência, 2005.

MATTOS, F. C. Da teoria à liberdade: a questão da objetividade em Kant. São Paulo: AM Produções Gráficas, 2009.

MOORE, A. W. "The Transcendental Doctrine of Method”. In: GUYER, Paul (Ed.). The Cambridge companion to Kant's Critique of Pure Reason. New York, USA: Cambridge University Press, pp. 310-26, 2010.

PATON, H. J. Kant's Metaphysic of Experience. (2 vols.) Londres: George Allen \& Unwin LTD, 2007 [1936].

PEREZ, D. O. Kant pré-crítico: a desventura filosófica da pergunta... Cascavel: Edunioeste, 1998.

SCHÖNFELD, M. The philosophy of the young Kant: the precritical project. New York: Oxford University Press, 2000.

SCHOPENHAUER, A. O mundo como vontade e como representação. $1^{\circ}$ tomo. São Paulo: Editora UNESP, 2005.

SMITH, N. K. "Kant's Method of Composing the Critique of Pure Reason". The Philosophical Review, Vol. 24, No. 5, p. 526-532, 1915.

SUZUKI, M. O Gênio Romântico. São Paulo: Iluminuras, 1998. 
TREVISAN, D. K. "Sentidos de metafísica na filosofia crítica de Kant". Studia Kantiana 17, p. 104-125, 2014.

WERKMEISTER, W. H. Kant, the architectonic and development of his philosophy. La Salle, USA: Open Court, 1980. 